\title{
Los saqueos y las ollas populares de 1989 en el Gran Buenos Aires. Pasado y presente de una experiencia formativa
}

\author{
María Rosa Neufeld' y María Cristina Cravino ${ }^{2}$ \\ Universidad Nacional de General Sarmiento - San Miguel y Universidad \\ de Buenos Aires - República Argentina
}

RESÚMEN: En la década del 1980, un nuevo fenómeno: las tomas de tierras o "asentamientos" transforma los procesos de urbanización en el Area Metropolitana de Buenos Aires. Los autores, miembros de un equipo de investigación de la Universidad de General Sarmiento (Argentina), entrevistaron a habitantes de estos asentamientos, y se sorprendieron con las frecuentes menciones a los saqueos y ollas populares ocurridos doce años atrás en un contexto de hiperinflación. En este artículo, estos hechos son considerados como constitutivos de una experiencia formativa iniciada con la organización para la toma de tierras y seguida poco después por los saqueos de supermercados y otros negocios durante la hiperinflación de 1989. Esto da origen, posteriormente, a las ollas populares que paliaron el hambre de ese momento, y que luego se transformaron en comedores comunitarios, guarderías y otras organizaciones que hoy persisten. Esta indagación se apoya en los relatos de los entrevistados y en la recopilación de diferentes periódicos de ese momento.

PALABRAS-LLAVE: asentamientos, saqueos, experiencia formativa, organizaciones comunitarias, memoria.

\section{Introducción}

En este artículo ${ }^{3}$ nos interesa referirnos a una preocupación que surge a partir de las entrevistas que estamos realizando, en el curso de 
nuestra investigación ${ }^{4}$, con habitantes de asentamientos del Conurbano Bonaerense. En las mismas, nuestros interlocutores hacen referencia recurrentemente a los saqueos y ollas populares ocurridos una década atrás en un contexto de hiperinflación. Esto motivó una serie de preguntas que intentamos responder: ¿Por qué se evocan con tanta fuerza hechos que tuvieron una característica notable: convirtieron a sujetos anónimos en protagonistas de situaciones locales que no se han olvidado, pero que al tiempo que sucedían en barrios puntuales, se repetían simultáneamente en otros espacios, principalmente en las importantes conurbaciones de Buenos Aires y Rosario 5 ? ¿ De qué manera estos hechos constituyeron una experiencia formativa? ¿Cómo vinculan los habitantes de estos barrios su situación actual - caracterizada por porcentajes altísimos de desempleo y el retiro de los planes sociales por parte del Estado - con estos hechos que se construyen en los relatos como un momento fundamental en la historia de sus barrios? ¿Qué relación tienen las organizaciones sociales presentes con las formas de respuesta a la crisis de hiperinflación de finales de los ' 80 ?

En la década del 1980 en el Area Metropolitana de Buenos Aires emergió un nuevo fenómeno que transformó los procesos de urbanización de la ciudad: las tomas de tierras o "asentamientos". Estos muestran nuevas conflictividades en torno de la ocupación del espacio urbano, producto de las transformaciones estructurales del mercado y del Estado. A su vez, dentro de ellos se construyeron tramas organizativas con el objeto de intentar superar su condición de ilegalidad - en cuanto a la tenencia de la tierra - y sus precarias condiciones de vida.

Este artículo se apoya en el análisis de entrevistas a pobladores de los asentamientos de la zona noroeste de Buenos Aires, específicamente de San Miguel y José C. Paz, complementadas con datos hemerográficos (diarios nacionales y locales) ${ }^{6}$. Estos dos distritos forman parte del aglomerado urbano denominado Gran Buenos Aires, compuesto por 25 municipios que rodean a la Ciudad Autónoma de Buenos Aires. Ambos se encuentran ubicados a una distancia aproximada de $40 \mathrm{~km}$ 
del centro de la ciudad. Ellos, junto al actual distrito de Malvinas Argentinas, constituían hasta 1995 el Municipio de General Sarmiento. San Miguel cuenta aproximadamente con 250 mil habitantes y José C. Paz con 215 mil $^{7}$. Se trata de dos municipios con características sociodemográficas distintas: el primero alberga, particularmente en la localidad de Bella Vista a sectores con niveles de ingreso medio-alto, su centro está habitado por sectores medios, mientras que en espacios periféricos (algunos de ellos a la vera del río Reconquista) se asienta población de escasos o escasísimos recursos. El segundo, presenta una composición más homogénea, contando con una porción minoritaria de sectores de condición socioecómica media en el centro de la ciudad y amplios espacios con población de escasos recursos prácticamente en todo el resto de su territorio.

En el Gran Buenos Aires, la crisis económica actual (que tiene su origen a mediados de la década del 1990) afectó de forma diferencial a los distintos municipios, contándose los distritos analizados entre los que presentan los índices más acuciantes. A modo de ejemplo, podemos mencionar que en mayo de 1997 mientras que el índice de desocupación era de 17,1\% para todo el Gran Buenos Aires, en José C. Paz ascendía a 24,3\% y en San Miguel al 21,4\% (Kohan \& Fournier, 1998).

Los saqueos ocuparon sólo un período corto de tiempo: unos días de fines de mayo y principios de junio de 1989. A simple vista pueden ser tomados como un episodio más de protesta, sólo recordado por la magnitud (se produjeron en casi todos los grandes conglomerados urbanos del país, aunque particularmente fuertes en el Gran Rosario y el Gran Buenos Aires) y por la conmoción y miedo que provocaron en el ánimo de todos.

Sin embargo, consideramos que fueron mucho más. Constituyeron un punto de quiebre en dos sentidos: por un lado, marcaron la antesala de la Reforma del Estado, ya que ésta se legitimó con el argumento de la crisis a la que los saqueos contribuyeron como imagen fantasmagórica de la hiperinflación. Por el otro, los saqueos dejaron huellas que no 
quedaron sólo en la memoria como hechos singulares, sino que fueron el comienzo de la construcción de toda una trama organizativa barrial tendiente a la resolución de la vida cotidiana. Cuando finalmente los ansiados víveres, producto de los saqueos o de los apresurados aportes de particulares y el Estado llegaron a los barrios, se organizaron una multiplicidad de ollas populares. Éstas se recuerdan como el origen de comedores, guarderías y otras organizaciones actuales.

A doce años de los episodios, la población en general no tiene el mismo registro de esta contracara de los saqueos - las ollas - que el recuerdo que guardan sus partícipes. Concordamos con quienes sostienen que "cada forma social viva es historia acumulada, rearticulada. Hacer inteligible el presente requiere buscar en el pasado el sentido de esas huellas"(Ezpeleta \& Rockwell, 1983). Concordantemente, Bosi (citado en el trabajo de James que reconstruye los hechos del 17 y 18 de octubre de 1945) afirma que

la memoria no es nunca, pues, una evocación pura y espontánea de los hechos o experiencias del pasado, tal como realmente sucedieron o como originalmente se los vivenció: implica un proceso permanente de elaboración y reelaboración de acontecimientos que tuvieron importancia pública y política, que siempre entrañan (...) una lectura social del pasado en los ojos del presente. (apud James, 1995: 104-5)

Aunque es difícil seguir, en los barrios en que trabajamos, los indicios de estas historias no escritas, fueron momentos cruciales que impactaron en la vida cotidiana de los habitantes de los asentamientos del Conurbano. Hay pistas a seguir que permiten establecer algunas conexiones: en primer lugar, la experiencia organizativa de las tomas de tierras. En segundo lugar, el contenido contradictorio de los recuerdos de nuestros interlocutores: un momento de fuerte unidad en el barrio y una situación de gran desesperación por la falta de medios para la subsistencia. En tercer lugar, la forma en que pasado y presente se unen para describir la situación actual de estos barrios, concretándose en organizaciones que surgieron como respuesta a la hiperinflación y aún hoy persisten. Este artículo irá recorriendo la presentación de estos tópicos. 
Revista de Antropologia, São Paulo, USP, 2001, v. 44 nº 2.

\section{Los Saqueos desde la reconstruccion a partir de diarios y entrevistas ${ }^{8}$}

En la actualidad, una de las constataciones cotidianas, en nuestro trabajo de campo, es cuánto conocen y cómo están pendientes los habitantes de los asentamientos acerca de las movilizaciones que, por razones similares, se realizan en otros lugares del país, a pesar de que estas personas, en gran medida desocupados, pasan la casi totalidad de sus vidas en estos asentamientos y zonas aledañas, y poseen sólo recursos limitados de comunicación (radios y televisores de modelos obsoletos). Un entrevistado demostraba su preocupación:

Se están palpando situaciones como lo que está sucediendo en Salta y están todos a la expectativa que es lo que va a pasar en Salta, si en Salta sale bien bueno se sabe ya que Jujuy habrá agarrado la manija Jujuy, ahora está Córdoba también, está Navarro, también y están todos como quien dice, creando de a poquito, poquito levanta viento a niveles sociales y se están creando respuestas, pequeñas respuestas pero dentro de las necesidades, es mucho. Y esperemos que no llegue a estos sectores así como digo yo somos los más marginados.

Sería ingenuo suponer que los diarios de la época nos cuentan "los hechos". Sin embargo, es posible reconstruir - a partir de esas páginas en las que los títulos van guiando nuestra mirada y nuestra comprensión, una serie de relaciones significativas, contrastables con los registros de campo. Sírvannos de ejemplo los significativos títulos de Página 12: "Desde el abismo", "La miniguerra civil", "La guerra de los machetes", "La batalla de las góndolas" (4 jun. 1989).

En estos artículos es posible rastrear las categorías con las que los periodistas reconstruyeron y otorgaron sentido a estos episodios. En algunos casos, hay un esfuerzo importante de conceptualización y análisis, que - al tiempo que se producían los sucesos - se aplicaba a contextualizar el uso que se estaba haciendo del término "saqueo":

En el principio fue el verbo saquear, que de este lado de la frontera está relacionado con delincuencia, con hordas y con gente de una raza diferente. 
Lo usan, por ejemplo, esos pequeños comerciantes que en minutos vieron arruinados años de esfuerzos (...) En otro escalón el verbo saquear es reiterado por los grandes comerciantes, la policía, los militares, los políticos, y hasta los izquierdistas. Algunos lo repudian, otros lo justifican. (Sergio Sciancaglini, “Desde el abismo", Página 12, 4 jun. 1989).

Según estos diarios, el 30 de mayo de 1989 se registraron hechos de tensión en el Gran Buenos Aires, que incluyeron concentraciones de vecinos y comerciantes que derivaron en el Municipio de La Matanza en enfrentamientos con la policía. En San Miguel, la policía informó haber detenido 268 personas por haber robado mercaderías en dos supermercados. Entre los detenidos figuraban 120 menores, y se destacaba que se utilizaron vehículos incautados al transporte público de pasajeros para transportar las mercaderías.

El día siguiente, 31 de mayo de 1989, en otra nota del mismo diario, se consideraba que estos hechos pasaron "a tomar la posta desplazando a Rosario en lo que hace a la gravedad de los disturbios que se iniciaron en el fin de semana" se estimaba (Carlos Alvarez, ministro de gobierno bonaerense) que "un 80 por ciento de las personas que saquean supermercados tienen un genuino problema social o directamente hambre, un 15 por ciento se compone de activistas de distintos partidos políticos (...) y el cinco por ciento restante pertenece a sectores que buscan la desestabilización del sistema" (militantes de izquierda y carapintadas) ${ }^{9}$.

En San Miguel se registraron cinco muertos, y unas 15 personas heridas de consideración ${ }^{10}$. Según el ministro de gobierno, habían actuado bandas armadas que incluso portaban ametralladoras. Las responsabilizó por el asesinato a mansalva de un colectivero que se negó a colaborar en los saqueos (...) Aunque los hechos fueron aislados, tuvieron su epicentro en San Miguel, partido de General Sarmiento y Moreno (...) Los problemas más graves se registraron en General Sarmiento, donde murió un pequeño de nueve años por un disparo en la cabeza. jHay una franja de tres kilómetros donde ya no hay nada que saquear! reconoció el intendente del partido, Eduardo Lóper, al tiempo que anunciaba la implementación de comedores populares para que la gente no responda a los activistas, que la llevan engañada. 
Ya el día 2 de junio, los informes periodísticos (Página 12, 2 jun. 1989) podían apreciar que el clima de convulsión había disminuido. Ahora, el problema era el desabastecimiento, que llegó a afectar la distribución de alimentos gratuita iniciada, entre otros, por los municipios. A todo esto, comenzaban a multiplicarse los comedores y ollas populares.

El gobierno había declarado el estado de sitio; sin embargo, los habitantes de los barrios La Paz, José C. Paz y Vucetich de General Sarmiento "reclamaban aún ayer mayor protección policial en horas de la noche, ya que de madrugada no se puede salir a trabajar por los asaltos".

El accionar de la policía, en el momento siguiente, (3 de junio de 1989) se concentró en el intento de recuperación de las mercaderías sustraídas, y en la detención de los supuestos culpables así como de los "activistas". En San Miguel "fueron secuestradas 400 botellas de vino, 600 gaseosas, jabón en polvo, fideos, 20 kilos de quesos y comestibles. En otros lugares se secuestraban escopetas, revólveres, bombas molotov. Y se detuvo a un grupo de once personas que los vecinos denunciaron por cobrarles protección" (Página 12, 3 ago. 1989).

Los saqueos habían generado un clima de "miniguerra civil", titulaba Página 12 el día 4 de junio. Ya no había saqueos, ni quedaba mercadería de la que apropiarse. Pero rumores persistentes aseveraban que unos barrios avanzarían contra los otros. Ya el objetivo no sería incautar las mercaderías de los comercios, sino las propiedades de los vecinos.

La prensa del momento, al igual que nuestros entrevistados, no tenía dudas acerca de quiénes idearon y fogonearon el miedo:

Los distintos uniformes de los ejércitos fueron acordados con la policía "para no confundirlos a ustedes"- le decían a cada barrio - "con los que vengan a saquearlos". La hipótesis funcionaba por un pequeño detalle: todos sabían que ya no había supermercados ni comercios sin saquear, por lo que la amenaza se volvía contra cada casa y cada rancho. El origen del rumor es confuso. Se habla de activistas de partidos de izquierda, pero un vocero policial admitió que "nosotros no desmentimos el rumor porque nos convenía que cada uno se quedara en el barrio, cuidándolo, porque de paso reducíamos el riesgo de que salieran todos otra vez a saquear comercios. 
El periódico concluía señalando que, finalmente, la miniguerra civil se había diluido, y destacaba el quiebre en lo cotidiano, las pérdidas materiales y humanas, y cómo las vivían los participantes:

El rumor de la guerra, sin embargo, fue lo suficientemente fuerte para que todos se quedasen en las barricadas y en las esquinas para evitar sorpresas. El efecto perverso de esta guardia fue que los hombres además de no comer, no dormían (...) El otro efecto fue que nadie iba a trabajar, perdiendo sus jornales. Sin dinero, sin comida, sin descanso, sin paz, los hombres de las barricadas disimularon sus armas por orden policial, y se quedaron comentando el saldo de la semana: "Tuvimos cuatro muertos solamente aquí, en San Miguel".

Los dos barrios a los que nos referimos habían surgido pocos años antes que los saqueos. Todos los entrevistados coincidían en evocar la historia de la constitución de los asentamientos, sus primeras organizaciones, surgidas como "comisiones internas" o "vecinales" - con diferencias en cada caso - y con el fin de abrir las calles, de ubicar a cada familia en su lote y de realizar toda una secuencia de acciones colectivas. Se recordaba con detalle la intensidad de las interacciones y la división de tareas entre los vecinos con el fin de resolver su vida cotidiana en condiciones habitacionales extremadamente precarias y encarar así su transformación en "barrio" al estilo de los que rodeaban a las tierras tomadas.

Como dijimos, los relatos acerca de lo ocurrido en los años 89 y 90 surgen espontáneamente en las entrevistas realizadas en el marco de la actual investigación, para explicar, comparar o comprender el presente. Sin embargo, esta reconstrucción no adquiere un carácter homogéneo o unilineal, por el contrario, presenta una elaboración del pasado que muestra sentidos contradictorios, casi dicotómicos.

En primer lugar encontramos que los hechos ocurridos en esos meses de 1989 y 1990 son presentados como un momento de confusión. Esto surge a partir de la dispersión de los rumores, que luego analizaremos y de la sensación de no saber quién era quién y qué sucedía en el exterior del barrio (que era vivido como un afuera peligroso). Estos recuerdos 
Revista de Antropologia, São Paulo, USP, 2001, v. 44 nº 2.

emergen a la memoria como vivencias de angustia y simultáneamente, de algo de "aventura". Los interrogantes acerca de quiénes fueron los actores y por qué intervinieron en la dispersión de estos rumores permanecen.

El tipo de recuerdo diferencia a quienes participaron de los saqueos, es decir obtuvieron literalmente bienes por la fuerza de los comercios en la zona de nuestro estudio, de aquellos que vivían en los barrios sitiados por el miedo y de quienes vieron transcurrir las escenas delante de sus ojos, pero desde el ámbito protegido a medias de los barrios cercanos. Por último, los comerciantes (de quienes no nos ocuparemos en este escrito), tampoco fueron homogéneamente afectados e involucrados.

Un segundo aspecto en el que coincide el conjunto de relatos es el otorgamiento de un sentido positivo a estos días, que se recuerdan como el momento de la construcción. Aquí encontramos en primer lugar la organización de las ollas, seguida luego por los comedores, que en muchos casos le dieron un sentido de trascendencia a las vidas de los protagonistas. A su vez, "el tiempo de los saqueos y las ollas" es reconstruido como un momento de unidad barrial, donde se dejaron de lado las orientaciones políticas, las trayectorias laborales pasadas y las creencias religiosas, etc., situación similar a la vivida en los primeros meses de las tomas de tierras.

Esta imagen contrasta con la percepción de "fragmentación" con la que nuestros entrevistados vivencian los barrios en la actualidad. En su mayoría son las mismas personas que vivieron la experiencia de unidad, pero que actualmente se encuentran "alejadas", "peleadas" o en bandos distintos, particularmente por participar de organizaciones políticas diferentes. A esto se suma que, en muchos casos, estas organizaciones que nacieron con las ollas ya forman parte del entramado político local, y giran en torno a sus clientelas.

El modo en que son presentados los hechos por nuestros entrevistados nos muestra cómo, a partir de los saqueos y las ollas, la vida cotidiana se vio alterada para siempre en estos espacios barriales. Al igual que 
el momento inicial de la toma de tierras, debían "unirse", pero esta vez para enfrentarse a un "enemigo" no muy claro. Similarmente, con sus acciones se posicionaron en la zona gris que desdibuja la ilegalidad jurídica de ambas situaciones (la toma de tierras y los saqueos) resituándolas en una disputa por cierta legitimidad social. Las entrevistas nos permiten ver cómo en estos actos cada sujeto aportó su experiencia y creatividad con el objeto de salir de la crisis que implicaba la falta absoluta de dinero y comida, y al mismo tiempo defenderse de la supuesta llegada de "hordas" de los barrios vecinos.

Nos propusimos respetar los tópicos que aparecen privilegiadamente en las entrevistas. Destaquemos que no hay en ellas "secuencias día a día". Más bien, dominan tres núcleos comunes: los rumores de un ataque de barrio contra barrio, la experiencia del miedo y la formación de las ollas populares. Respetaremos, pues, esta estructuración de sentidos. Señalemos, además, que en los recuerdos estos sucesos son presentados fuera de toda matriz política. En un solo caso, excepcional, un vecino abordó la cuestión de la supuesta presencia de agitadores, desmintiéndola. Esto nos permite contrastar los relatos de los entrevistados con el discurso de las autoridades, que por los medios de comunicación masivos culpabilizaron de los saqueos a "agitadores" y "delincuentes" (Iñigo Carrera, 1995; VVVA, 1999) ${ }^{11}$.

\section{Los rumores: barrio contra barrio}

Como ya vimos a partir del registro hemerográfico, en esos días los rumores fueron también centro de la escena. La energía que demandó dispersarlos fue tan importante como la dedicada a la resolución de la alterada vida cotidiana ${ }^{12}$, que justamente perdía el sentido de lo cotidiano. Las "reglas ausentes" a las que hace referencia Horstein (1993) en los momentos de hiperinflación permitieron, facilitaron y cultivaron los rumores en un contexto en el que "todo es posible" y por lo tanto "todo es creíble". Sin embargo, "los rumores" parecen haber surgido 
Revista de Antropologia, São Paulo, USP, 2001, v. 44 nº 2.

deliberadamente. Una sola chispa era suficiente para provocar el incendio. Un entrevistado sintetizó la situación como: "En ese momento lo único que existía era la desconfianza".

A pesar del paso del tiempo, luego de doce años, nuestros entrevistados resaltaron claramente el origen de los mismos. En primer lugar, identificaron como policías a quienes "sembraban" los rumores:

Esto lo hizo el servicio de inteligencia que le ordenó a la policía que pasara por los barrios y que dijeran que se quedaran en sus casas porque los otros barrios venían saqueando las casas y quemando, violando y matando gente. Yo corrí como loco gritando "las mujeres y los chicos adentro y los hombres afuera que vienen los de los otros barrios, vienen a saquear, a violar a matar". No sabés (...) casi me enfermo (...) casi me agarro un paro. (José, San Miguel)

El recuerdo de la organización de las barricadas y piquetes surge vívidamente:

Entonces en cada cuadra había 8, 10 tipos $^{13}$ armados, escopetas, pistolas, revolver, machete, cuchillo, y fogonata. Mirá lo que hice yo: me fui hasta "Mitre" (villa miseria cercana) (...) había una cinta a lo largo que cruzaba toda la calle, y estaba todo oscuro, y me dicen "quedate quieto", y yo les dije "está bien no tiren," soy del Barrio Las Calas, vine a hablar". Se me acercaron cuatro tipos y me apuntaron con un revolver en la cabeza. "Está bien flaco, no pasa nada, soy de Las Calas, yo venía a ver si ustedes venían para el barrio de nosotros, yo soy del cuerpo de delegados". "No", me dice, "ustedes son los que se vienen para acá". "No", le digo, "nosotros estamos quietos ahí esperando que ustedes vengan, no nosotros estamos todos quietos acá." Me dice el muchacho, "mirá para que no nos confundamos y no nos matemos entre nosotros, pónganse una cinta blanca en el brazo y cuando vengan para este lado digan XX blanco, y nosotros vamos a decir, blanco Mitre, entonces sabemos que somos de esta zona, lo mismo va a decir Trujuy"(otro barrio cercano). Entonces ya fui con esa tranquilidad, al resto vos lo veías a todos con el brazalete blanco, después me fui a la otra punta, venía un patrullero con cuatro policías al costado con itacas (ametralladoras) en la mano, yo me iba para la otra punta, y veo que vienen los policías y retrocedo y les digo a la gente "arréglense", y me meto entre la gente y pasaron los vigilantes, porque no sabíamos si eran vigilantes o qué, porque andaban de civil, ni a los vigilantes les teníamos confianza, y saludaban. (José, San Miguel). 
Esto es coincidente con los relatos que en su momento presentaba el diario Página 12 del 4 de junio de 1989:

José María, de 22 años, fue uno de los que en la Villa Mitre se sacó la camisa, cuando ya no había saqueos pero existía el rumor de la invasión a la villa desde otras, como Primavera, Santa Brígida y Vucetich. En las otras villas existía el mismo rumor pero al revés: los de Mitre serían los invasores. Cada barrio armó barricadas para defenderse, manzana por manzana. Toda esa zona reúne unas 150.000 personas que el miércoles estaban en pie de guerra unas contra otras. En Mitre se quitaron las camisas. En Primavera usaban vinchas blancas. En Vucetich un brazalete. En todos lados tenían cuchillos, machetes de medio metro de largo y una interesante dosis de escopetas y pistolas.

Volviendo al relato de nuestro entrevistado, éste se hizo cargo de informarles a todos que volvía la calma: "de ahí me fui por todo el fondo, fui a notificarles a todos, ya había más tranquilidad, me acuerdo que llevé un fierro grueso que yo le decía el "amansa a locos" tenía una boca que parecía una escopeta del 16 con una cadena, con eso yo hacía que era una escopeta, no tenía armas" (José, San Miguel). A partir de aquí, detallaba una serie de encuentros con vecinos de barrios cercanos, cargados de gran tensión y miedo así como momentos dramáticos, por ejemplo, la atención de un parto de una mujer que no podía llegar al hospital a tiempo.

Las categorías utilizadas por los entrevistados son precisas: una de ellas, guerra civil, coincidente con la utilizada por los medios de comunicación de aquellos años. Los entrevistados nos dijeron: “Te digo, que donde había un solo muerto esa noche, iba a ser una guerra civil. No sé si pensaron en eso los vigilantes (policías)" (José, San Miguel). Otra vecina, utilizó palabras similares: "No se armó una guerra civil esa vez porque Dios fue grande” (Mónica, José C. Paz).

Juana, de José C. Paz: "pero ahora nos preguntamos ¿quién era los que venían, quiénes? Incluso por ejemplo unos papás que estaban en la esquina, a cinco esquinas más, estaban con una identificación en el brazo como que eran de este barrio, los mismos papás que cuidaban cada 
esquina, que se identificaban con la cinta, era nuestra identificación(...) ¡Y ya vienen!¡Ya vienen!”. Su afirmación en tiempo presente nos muestra que las dudas sobre lo sucedido en esos días persisten, como si el relato oficial o el de los rumores no estuvieran suficientemente aclarados, faltando quien dijera la verdad.

Una entrevistada de un barrio aledaño a un asentamiento recordaba, en particular el paso de automóviles con la bandera argentina (¿qué significado tenía portar ese estandarte?) cuyos conductores decían "dentro de una hora va a venir el barrio tal, está viniendo". Esta mujer los asociaba a "terroristas"

Merece resaltarse el sentido que tenían estos rumores: fijaban a cada persona en su casa, con miedo al exterior, al vecino del barrio cercano, sólo confiando en la ayuda de quien vivía en el propio. Esto permitiría, un mejor control de la población por parte de las autoridades y, supuestamente, impediría nuevos saqueos.

\section{La experiencia del peligro}

La vida diaria estaba totalmente trastocada, a tal punto que una vecina afirmó: "yo hice tantas cosas raras en ese tiempo". Horstein (1993) en un artículo escrito en los momentos de la hiperinflación señala: "Nadie sabe hoy cuál es el lugar que tiene en la sociedad, pero lo que es más grave aún, nadie sabe qué lugar tendrá cuando el fenómeno cese. Cunde la desconfianza, ya que las reglas del juego, tanto económicas como sociales, cambian tan vertiginosamente que más que reglas cambiantes, son reglas ausentes" (1993: 230).

Los saqueos, sin duda, produjeron, un sentimiento generalizado de miedo. Aquellos que habitaban los barrios del centro de la ciudad y los de clase media temían la invasión de una "masa humana hambrienta" que vendría a saquear (a esto hacen referencia los medios gráficos). Sin embargo, en las "villas miseria" (favelas) y asentamientos del Conurbano Bonaerense, lo mismo que en otras conurbaciones de las principales 
ciudades del país, el miedo tuvo consecuencias concretas y provocó acciones defensivas y ofensivas organizadas.

Cual si fuera un naufragio, las mujeres y los niños eran considerados los más "vulnerables" y los hombres eran los "responsables" de la protección de los distintos barrios. Los periódicos mostraron fotos refiriéndose a "ejércitos", que podían verse portando palos y cuchillos, al mismo tiempo que policías fuertemente armados defendiendo los supermercados.

Una entrevistada que participó directamente de los saqueos nos relató:

Y después, no sé, nos escuendíamos todos(...)Cada marido, ¿no? hacía la guardia en las esquinas por los hijos, porque decían que la casa no era tan segura y teníamos que correr (...) un día me refugié allá, en una casa (...), que era como una linda casita, y que era como decir, de losa, era como reforzada, y entonces nos metíamos todos ahí (...) la señora nos permitía (...) jestuvimos tres días, tres noches así! No dormíamos, los papás y las mamás... (Teresa, José C. Paz)

Los rumores apuntaban centralmente a aquellos que habían participado de los saqueos, tal como una vecina recordó. Esto llevó inclusive a situaciones tan extremas como la que nos comentó la citada entrevistada: "Yo ya estaba cavando un pozo atrás de mi casa para poner a mis hijos, del miedo que me hacían dar"!

\section{La organización de las ollas populares}

Esta segunda imagen, la de la construcción, rescata los recuerdos de 1989 como momentos en que se vivió la experiencia de la unidad, de la construcción de organizaciones que, apelando a la solidaridad, permitieron afrontar la crisis que provocó la hiperinflación. Así, las entrevistas destilan cierta nostalgia, frente al presente, que se vive como signado por la política partidaria y la desunión consiguiente. En los doce años transcurridos, se agregaron además las modificaciones en la territorialidad 
Revista de Antropologia, São Paulo, USP, 2001, v. 44 nº 2.

y los actores y mediadores barriales, generadas por la implementación de diversos planes sociales (Cravino et al., 2000).

La filiación entre los saqueos, las ollas y los comedores que hoy se observan en los barrios es explícita:

El comedor comunitario fue creado a partir de los saqueos, en ese entonces ya estaba creada la Capilla, y ahí en la época de los saqueos vino un bajón, los comercios no tenían mercaderías existentes y nada por el estilo y nos vimos en la necesidad de crear una fuente de alimentación, organizar algo para poder dar de comer (...) viene a ser a criaturas, gente, madres embarazadas, madres solteras, familias en sí pero pertenecientes a este barrio. Nos han facilitado la Capilla para hacer una olla popular (Gonzalo y Teresa, José C. Paz).

La presencia de las ollas populares es el aspecto menos destacado por los medios de comunicación, sin embargo fue el de mayor impacto en la vida cotidiana. Se obtenían los alimentos de diferentes formas ${ }^{15}$ : estaban los aportes de los que tenían algún ingreso, de los que habían acopiado en los saqueos, pero mayoritariamente los municipios y comerciantes de la zona eran los que "colaboraban"16. Cada día había que empezar de nuevo. Como un punto de quiebre, a partir de ese momento, los municipios comenzaron a ser proveedores de alimentos - de forma continua y/o discrecional - en una situación de "emergencia" que devino en permanente ${ }^{17}$.

Las respuestas de los comerciantes ${ }^{18}$ no fueron homogéneas respecto del "perdón" a los saqueadores o del apoyo a las ollas. Gonzalo, de José C. Paz nos dijo: "había almaceneros que te miraban a la cara y ya por la cara sabían de dónde sos, de qué sector sos, de que te vean venir de que lado venís. Vas acá a dos cuadras y si te veían salir de acá no te dan absolutamente (...) te bajaban las persianas, la gente asustada por la circunstancia que había pasado".

En algunos casos las ollas surgieron en lugares públicos y en otros en las mismas casas de quienes tenían la iniciativa. Un entrevistado nos dijo:

$y$ se fue creando, haciendo a los ponchazos, consiguiendo por intermedio de la nación de la municipalidad de Gral. Sarmiento ollas, esas ollas de 100 litros, 
las morochitas, las negritas les decíamos nosotros porque daban asco como quedaban. Hacíamos el desayuno, al mediodía el almuerzo, a la tarde la merienda y a la noche la cena. No era gran cosa lo que se daba y por eso mismo hacíamos (...) le brindábamos a la gente la posibilidad de poder comer al mediodía y comer a la noche porque aparte que las comidas no eran de suma alimentación porque mezclábamos todo, dada la necesidad mezclábamos, hacíamos un guiso y servían en ollita que esto que el otro y después mezclábamos todo, arroz, fideos para que alcancen para todos, te digo que eran 2.000 personas, 2.000 bocas, que se asistían. (G., José C. Paz)

Las cifras de los asistentes eran importantes, pero los recuerdos de ese momento destacan la organización alcanzada para paliar la escasez de recursos. Gonzalo recordó:

no teníamos cocina, no teníamos nada, era todo a leña, nos hemos cansado, de sacar ampollas en las manos de hachar árboles, no había árboles acá, no había quedado un árbol en pie, a pesar de saquear los negocios hubo saqueo absoluto de árboles. Entrábamos a las casas, (...) entrábamos mediante el permiso viene a ser, de los propietarios, no era una situación creada por diversión o por activismo diferente, no la gente veía de que (...) se pasaba y se veía que los chicos comiendo en la vereda porque no daba abasto el espacio, los sentábamos a todos en la vereda, en lo que era el patiecito que tiene la construcción de la Capilla, y era todo un humerío, en medio del humo de la leña porque cocinábamos ahí adentro, hacíamos fuego ahí adentro, y también mezclado con aquellos evacuados porque ya habíamos creado un grupo tan sólido de trabajo, que éramos 20 y éramos 20 para todo, viene a ser nos dividíamos entre nosotros, ustedes se van a encargar hoy de ir a hachar leña, de buscar leña hay que procurar para mañana a la mañana, entonces se iban a la tarde.

La experiencia, en algunos casos, dejó una organización que deliberadamente no quizo ser desaprovechada, pero multiplicada en diferentes iniciativas ${ }^{19}$.

\section{En el final: el pasado en el presente}

Los medios de comunicación mostraron a los saqueos como un momento de protesta, con un inicio y con un fin. Sin embargo, las entrevistas destacaron la historia de constitución y construcción de cada uno de 
Revista de Antropologia, São Paulo, USP, 2001, v. 44 nº 2.

los barrios y su continuidad organizativa en los momentos de los saqueos y las ollas populares. La estructuración de la trama de organizaciones presentes en cada uno de ellos - guarderías, comedores, centros de atención de Cáritas (Iglesia Católica) y de otras iglesias - se inscribe entonces, tanto en los momentos iniciales de la toma de tierras, como en los dramáticos hechos de los saqueos y las ollas.

Como dice Tilly ${ }^{20}$ (2000) la definición acotada de "acción colectiva" debe ser relativizada teniendo en cuenta, entre otras cosas, que no existen fronteras precisas entre lo que es rutina y lo que extraordinario; que la acción muchas veces depende en parte de relaciones sociales pre-existentes; que los actores de acciones colectivas participan de negociaciones e improvisaciones. Es decir, el repertorio no está totalmente prefijado de antemano. Si bien este autor se refiere exclusivamente a la historia europea, resulta útil tomar su reflexión en relación a que sus protagonistas

"consiguieron la mayoría de sus acciones colectivas mediante instituciones y prácticas que ellos mismos inventaron, tomaron prestadas, o adoptaron durante su experiencia histórica (...) algunas de estas instituciones y prácticas emergieron de intentos más o menos deliberados por coordinar acciones colectivas, los sindicatos y las asociaciones revolucionarias surgen de "esa preocupación". Sin embargo, muchas de ellas fueron un subproducto de la interacción social rutinaria (: 10).

Los actores de estos asentamientos del Conurbano compartían la experiencia de la constitución del barrio como un hecho de construcción colectiva, donde conocieron la reciprocidad, y/o la organización para la superación de las adversas condiciones habitacionales, aunque con dinámicas organizativas y vínculos con las instituciones de "fuera" del barrio diferentes entre los dos casos analizados. Los partidos políticos tenían presencia, pero parecían estar en un segundo plano, a diferencia del presente en el que éstos disputan o cruzan este entramado organizativo.

No coincidimos con las teorizaciones que presentan a los saqueos y las ollas como respuestas "espontáneas" de los habitantes de los 
asentamientos y "villas miseria" (favelas) del Conurbano. E. P. Thompson con su concepto de "economía moral de las masas" se opone a las visiones economicistas o mecanicistas que asocian de forma directa hambre y motín. Por el contrario, este proceso de la protesta aparece mediado por las representaciones de los sujetos involucrados en estos hechos. Destaca, además, la centralidad de la noción de legitimidad sobre la base de derechos cuyos límites están fijados cultural y socialmente:

Es posible detectar en casi toda acción de masas del siglo XVII alguna noción legitimante. Con el concepto de legitimación quiero decir el que los hombres y las mujeres que constituían el tropel creían estar defendiendo derechos o costumbres tradicionales, y en general, que estaban apoyados por el amplio consenso popular era confirmado por una cierta tolerancia por parte de las autoridades, pero en la mayoría de los casos, el consenso es tan marcado y enérgico que anulaba las motivaciones de temor o respeto. (Thompson,1995)

Claramente, la imagen de los saqueos no pertenece al pasado. Fue utilizada recurrentemente como metáfora para la descripción de la gravedad de la situación actual. Dos tramos de los relatos de los entrevistados son elocuentes. Gonzalo (José C. Paz) nos dijo:

Acá por lo menos, no sé si ustedes están recorriendo los barrios de mayor necesidad, donde más se está creando este tipo de situaciones, que se comenta algo el tema de las posibilidades que antes de las fiestas (...) y ya la gente acá es un revuelo, acá ya la gente hoy por hoy viene a ser está palpando que algo se viene, algo se acarrea entre manos a niveles políticos. Viene a ser porque la subsistencia no le da a nadie para llenar la panza de nadie y nada por el estilo.

Raquel (José C. Paz) afirmó “es tal la desesperación de la gente por la falta de trabajo, por la miseria que hay, que tenemos miedo de volver a los saqueos, esto va a estallar, vamos a volver a los saqueos". Y seguidamente separa esta afirmación de toda posible connotación política "La gente dice la política no está conmigo".

Nos encontramos en un momento en el que las semejanzas y vínculos entre 1989 y el presente permiten que nuevamente los rumores aparezcan, 
Revista de Antropologia, São Paulo, USP, 2001, v. 44 nº 2.

dando vitalidad al fantasma de los saqueos y recreando los límites de la legitimidad social. Sin embargo, en este caso los hechos se presentan insertos de manera distinta dentro de la trama política local y provincial. Tal es el caso del que informa un diario local del 27 de julio de $2001^{21}$, en su nota denominada "Ishi (intendente actual de José C.Paz) insiste que hubo saqueos"22. Aquí podemos presumir que la polisemia de la palabra "saqueos", que en este caso provino de la jerga policial en relación a actos de robo, permite un uso resignificado, debido a la actual condición de posibilidad, como "saqueos" en los términos ocurridos en 1989. El diario Clarín del 24 de junio de 2001 retomó esta polémica acerca de cómo caracterizar a los hechos y afirmó en el artículo titulado "El saqueo que nunca se produjo"que "Clarín no encontró prueba alguna de que efectivamente haya habido saqueos (: 8)". El deslizamiento de significados no fue casual. El mismo día del supuesto hecho se realizó un "piquete" en una avenida cercana en protesta al deterioro de dicho acceso - fundamental en la comunicación dentro del municipio, donde abundan las calles de tierra, en condiciones intransitables. Continúa la crónica, recreando el pasado en el presente:

Hay rumores de que los piqueteros vienen hacia la zona saqueando comercios. Las madres toman a sus hijos de la mano y se van de la zona. Algunos comercios bajan las persianas por precaución. Otros siguen, como si nada. Son sólo rumores. Incluso, entre quienes propalan los rumores se encuentran policías, pese a que luego la misma Policía admita que no hubo denuncia ni investigación judicial alguna de saqueos.

El jefe municipal para darle mayor credibilidad a sus afirmaciones recurrió al pasado: "acá empezaron los saqueos en el 89".

No sólo los funcionarios pueden presionar con esta posibilidad, sino también - algunas organizaciones sociales del Conurbano Bonaerense. El diario Página 12, del 9 de septiembre del presente año, reprodujo la afirmación de un dirigente de la Corriente Clasista y Combativa del Municipio de La Matanza: "No queremos que ocurran los hechos violentos de 1989. El pueblo está más armado que antes y no queremos 
que corra sangre. De esto estamos alertando a todos los gobernantes". Esto se apoyaba en un diagnóstico de la situación, coincidente con lo afirmado por nuestros entrevistados ${ }^{23}$ : "Hay una desesperación terrible en los barrios. Nuestros compañeros comen salteado y nos piden que salgamos a buscar comida. En la Matanza el presupuesto de los comedores se ha reducido en un $80 \%$ (...) El dirigente propuso una nueva modalidad de obtención de alimentos: "Para paliar ese hambre, Alderete reconoció que pedirán alimentos a los supermercados "por nota".

Esta nueva presencia del término "saqueo", como rumor, como posibilidad, como amenaza o como metáfora permite percibir hasta qué punto los hechos de 1989 fueron una experiencia formativa para los sujetos involucrados. Los saqueos quedaron instalados, en la memoria de todos, como un horizonte de posibilidad. Y cuestionan el abordaje, simplista a nuestro modo de ver, de aquellos que los consideraron como "protestas episódicas".

\section{Notas}

1 E-mail: mneufeld@ciudad.com.ar. Facultad de Filosofía y Letras, UBA.

2 E-mail: ccravino@ungs.edu.ar o criscrav@hotmail.com. Universidad Nacional de General Sarmiento.

3 Presentado originalmente como ponencia en el IV RAM, Reunião de Antropología do Mercosul, en el Forum "Desafios contemporâneos da antropologia urbana", Curitiba, 11 a 14 de noviembre de 2001.

4 La presente ponencia es producto de un trabajo de investigación más amplio que se está desarrollando en el Area Condiciones de Vida y Políticas Sociales del Instituto del Conurbano de la Universidad Nacional de General Sarmiento. El equipo está dirigido por María Rosa Neufeld (antropóloga) y está compuesto por María Cristina Cravino (antropóloga), Marisa Fournier (socióloga) y Daniela Soldano (politóloga). 
5 Ver, por ejemplo, VVAA (1999).

6 El archivo hemerográfico fue confeccionado por la estudiante María Rosa Silva.

7 Los datos estadísticos que aportan cifras desagregadas por municipios son los proporcionados por el Censo de Población y Vivienda realizado por el INDEC (Instituto Nacional de Estadísticas y Censos). Los datos disponibles corresponden al censo realizado en 1991, cuando aún los municipios de San Miguel, José C. Paz y Malvinas conformaban el Partido de General Sarmiento. En el presente año se realizó un nuevo censo cuyas cifras aún no se procesaron.

8 El corpus hemerográfico con el que trabajamos está integrado por las ediciones de los últimos días de mayo y la primera quincena de junio de 1989 de Página 12, Clarín y La Nación (de circulación nacional), del periódico Pueblo (editado por la Unidad Popular, y de circulación en el entonces municipio de General Sarmiento), dos números de junio y julio de 1989 de la revista de la Asociación Comercial y una serie de diez números del diario local La Hoja de San Miguel, editados en 1999 (a diez años de los saqueos), así como artículos de 1989 de La Prensa, Crónicay Nación.

9 Durante los gobiernos de Raúl Alfonsín (1983-1989) y los primeros años de Carlos Menem (1989-1999), hubo alzamientos militares cuyos protagonistas fueron denominados "carapintadas", haciendo alusión a los camuflajes bélicos que utilizaban.

10 Médicos del Hospital Larcade, de San Miguel, nos relataron aquellos momentos, afirmando que ese nosocomio se convirtió "en hospital de campaña", atendiendo a los heridos en los enfrentamientos y saqueos.

11 Nos parece interesante relacionarlo con las conclusiones arribadas por James cuando afirma que "el 17 de octubre no estaba manchado por ningún vínculo con la política tradicional y con los intereses particulares. Dentro de este contexto, admitir algunos de los hechos violentos y turbulentos acaecidos en esa jornada habría empañado la legitimidad y la autenticidad del significado simbólico que llegaron a tener". (1995: 106)

12 Hornstein afirmaba "el trabajo habitual, hasta el más calificado, parece improductivo. La especulación pasa a ser la única forma de preservarse de la inflación, nunca el 
trabajo. Lo cotidiano es invadido por lo económico. Todo argentino se ha convertido en un broker" (1993: 230).

13 En el lenguaje popular equivale a "hombre".

14 'Nos decía: 'para poner a un pueblo a un barrio así con ese terror, serían terroristas' (Mónica, José C. Paz). Si bien llamativamente no aparecen en los relatos los "activistas" (para confirmar o refutar los que afirmaron una y otra vez las autoridades y los medios de comunicación) esta entrevistada afirmaba que estas mismas personas "(hablábamos con mi marido) eran tipos que le iban dando armas a la gente".

15 Un entrevistado nos mostró un minucioso registro de lo entregado, de lo comprado, de quiénes recibían alimentados. Nadie podía prever como continuaría la historia y si alguien exigiría rendición de cuentas.

16 Gonzalo (José C. Paz) nos dijo: "los requeríamos de Municipalidad, de donaciones que hacía la gente, la gente aquella que habían participado muy directamente con los saqueos, viene a ser, los que mayor parte se habían llevado venían y colaboraban a sabiendas de que había una necesidad unánime viene a ser mayormente criaturas era los que se intentaba asistir. Nos facilitaban harina, fideos, polenta, todo tipo de cosas para poder armar algunas comidas. Íbamos a manguear a los comercios y nadie quería dar nada, pero había así algunos entre tantos recorridos que pegábamos que venían y nos daban".

17 Prevot Schapira afirma que: "La interrupción del Plan Alimentario Nacional (PAN) en el momento de mayor hiperinflación (mayo de 1989) obligó al gobierno provincial y las municipalidades a responsabilizarse de la asistencia alimentaria: ollas populares, comedores comunitarios, distribución de víveres" (1993: 790). Señala M. Chiara (2000) que, si bien no se produjeron modificaciones en el status de los municipios del Conurbano, a partir de la hiperinflación de 1989 se modificaron las condiciones y las funciones que ejercieron, que hasta ese momento sólo se concentraban en el primer nivel de atención de la salud y algunas actividades de cultura y deporte. Las procesos que modificaron las condiciones principalmente son tres: "la caída de los recursos, la consecuente rigidización del gasto a la baja y la ampliación de las plantas en términos agregados". En cuanto a las nuevas tareas posteriores a la hiperinflación menciona el Bono Solidario y el Plan País. 
Revista de Antropologia, São Paulo, USP, 2001, v. 44 nº 2.

18 En los municipios del noroeste del Conurbano, nuestras zona de estudio, los comerciantes elevaron cartas a las autoridades y demandaron indemnizaciones.

19 Podemos citar la experiencia de Juan (San Miguel): "Después me preocupé por hacer un horno de pan, que lo hice acá en mi casa, un grupo de 10 familias. Eso nos ayudaba la asociación civil $\mathrm{X}$, era una institución que nos ayudaba”.

20 "Los historiadores sociales y los científicos sociales generalmente reservan el término 'acción colectiva' para episodios que comprometen a participantes que no actúan juntos de modo rutinarios y/o que emplean medios de acción distintos que adoptan para la interacción cotidiana. En este sentido acotado, la acción colectiva se parece a lo que otros analistas llaman protesta, rebelión o disturbio" (Tilly, 2000: 10).

21 Ya en mayo del 2000 hubo una serie de incidentes a partir de las afirmaciones de un concejal del Frepaso del municipio de San Miguel. Dicho edil desmintió y afirmó que sus palabras fueron malinterpretadas (La Hoja, 31 may. 2001, p. 5).

22 Se afirma: "Mario Ishi dio una conferencia de prensa. Además de explicar la dramática situación económico social del distrito, volvió al tema de los saqueos, que él mismo había anunciado que había ocurrido en el distrito de junio: 'Quiero aclarar a los periodistas que hablaron y decirles que si yo digo que hubo saqueos es porque los hubo y lo sostengo. Lo digo porque tengo documentación de la polícía que me manda al municipo, donde dicen que a las 19 estaban saqueando en la Avenida Croacia"'.

23 A modo de ejemplo podemos citar lo dicho por Rosario (José C. Paz), trabajadora de una guardería infantil: "En todas las Escuelas de la zona no cuentan con comedor, y los que existen no dan abasto, son deficientes. Los chicos comen apurados porque vienen los otros atrás, a veces si son tres de una familia come uno y el resto espera afuera". Agregó que "una asesora del gobierno provincial" les dijo, que "no inventen más comedores comunitarios, que no va haber más fondos". 


\section{Bibliografia}

ACHILLI, E.

Escuela, familia y pobreza. Acerca de la experiencia formativa de los niños, Rosario, CRICSO.

AUYERO, J.

2000

"El juez, la reina y el policía. Etnografía, narrativa y los sentidos de la protesta", en Apuntes de investigación, Buenos Aires, Cecyp.

CHIARA, M.

2000

"Las políticas sociales en el Gran Buenos Aires en los noventa. Algunas reflexiones acerca del régimen local de implementación”, México, Revista Quivera, n. 4, año 2. México.

EZPELETA, J. \& ROCKWELL, E.

1983

"Escuela y clases subalternas", Cuadernos políticos, n. 37, Editorial Era, jul.sep.

FARINETTI, M.

2000

"Violencia y risa contra la política en el Santiagueñazo. Indagación sobre el significado de una rebelión popular", en Apuntes de investigación, Buenos Aires, Cecyp.

KOHAN, G. \& FOURNIER, M.

1998

La situación local. La inserción laboral de cuatro partidos de la Región Metropolitana de Buenos Aires, San Miguel, ICO/UNGS.

GUINZBURG, C.

1994

Hitos, emblemas, indicios, Barcelona, Gedisa.

HORSTEIN, L.

1993

Práctica psicoanalitica e historia, Buenos Aires, Paidós. 
Revista de Antropologia, São Paulo, USP, 2001, v. 44 nº 2.

INIGO CARRERA, N. ET AL.

1995 La Revuelta, Argentina 1989-1990, mimeo.

JAMES, D.

1995

"17 y 18 de octubre de 1945: el peronismo, la protesta de masa y la clase obrera argentina”, en TORRE, J. C., El 17 de octubre del 45, Barcelona, Ariel.

\section{PREVOT-SCHAPIRA}

1993 "La consolidación municipal en el Gran Buenos Aires: tensiones y ambiguedades”, Estudios Sociológicos, México, vol. XI. (33), set.-dic.

ROMERO, J. L.

1991 "Los sectores populares urbanos como sujeto histórico", Cuadernos del Instituto Nacional de Antropología, Buenos Aires, n. 13.

SALTALAMACCHIA, H., CÓLON, H., RODRÍGUEZ, J.

1983 "Historia de vida y movimientos sociales: propuesta para el uso de la técnica”, Iztapalapa, n. 9, jun.-dic.

SALVATORE, $R$.

1995 "Reformas de mercado y el lenguaje de la protesta popular", Revista Sociedad, n. 7. oct.

THOMPSON, E. P.

Costumbres en común, Barcelona, Crítica.

TILLY, C.

2000

"Acción colectiva", Secyp. Apuntes de investigación, n. 6, año IV, nov.

VVAA

1999

A diez años de los saqueos en Rosario - crisis social, medios y violencia, Rosario, CECYT/CEHO/UNR. 


\begin{abstract}
In the eighties, a new phenomenon transforms the urbanization processes of the Metropolitan Conurbation of Buenos Aires: settlements on private or public lands. The authors, members of a research team of the University of General Sarmiento (Argentina), interviewed the inhabitants of these settlements and were surprised by the frecquent mentions to the saqueos (pillages/plunderings) and ollas populares (popular stens) which happened twelve years ago, in a context of hiperinflation. In this article, these facts are considered as constitutive of a formative experience iniciated by the organization after the takeover of the lands, followed by the plunderings to the supermarkets and other stores during the hiperinflation of 1989. It gives place, afterwards, to comedores populares (communitary dining rooms) and guarderias (kindergardens), so as other organizative means that began as a response to the hiperinflation and still exist. Our inquiry leans on the narratives of the settlers and different newspapers of that time.
\end{abstract}

KEY-WORDS: settlements, plunderings, formative experience, communitary organizations, memory. 